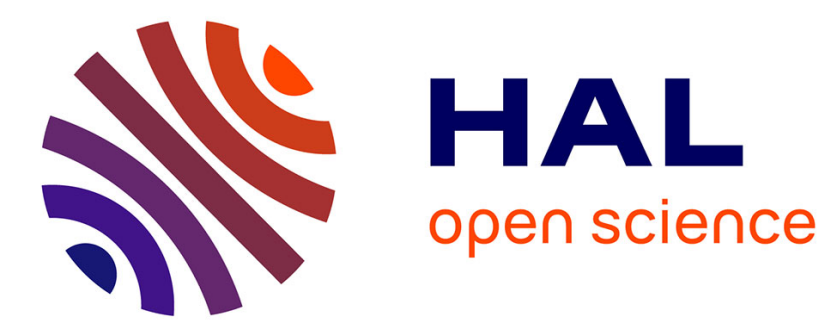

\title{
Cognition and Routine Dynamics
}

Nathalie Lazaric

\section{To cite this version:}

Nathalie Lazaric. Cognition and Routine Dynamics. Feldman, M. Pentland, B., D'Adderio, L., Dittrich, K. Rerup, C., Seidl, D. Cambridge Handbook of Routines Dynamics, Cambridge University Press, 2021. halshs-03402421

\section{HAL Id: halshs-03402421 https://shs.hal.science/halshs-03402421}

Submitted on 25 Oct 2021

HAL is a multi-disciplinary open access archive for the deposit and dissemination of scientific research documents, whether they are published or not. The documents may come from teaching and research institutions in France or abroad, or from public or private research centers.
L'archive ouverte pluridisciplinaire HAL, est destinée au dépôt et à la diffusion de documents scientifiques de niveau recherche, publiés ou non, émanant des établissements d'enseignement et de recherche français ou étrangers, des laboratoires publics ou privés. 


\title{
Cognition and Routine Dynamics
}

Nathalie Lazaric, Université Côte d'Azur, CNRS, GREDEG, France \& School of Business, Economics and Law, University of Gothenburg, Sweden.

\begin{abstract}
Cognition is critical for finding different solutions to problems and providing new, robust patterns of action for the performance of routines. Routine Dynamics research provides significant empirical evidence about patterns and performance, and reveals how practices are permanently co-shaped using the notions of artefacts, reflection, replication of knowledge and intentionality. The notions of reflective action and reflective thinking have been identified as critical for current patterns of interdependent actions, thus offering an opportunity to reshape both cognition and the representation of routines that is far from the original conception of the Carnegie School.
\end{abstract}

\section{Introduction}

The debate about cognition started with the Carnegie School which put this notion at the center of the routines' discussion (Cohen, 1991; Cyert and March, 1963; Nelson and Winter, 1982; Simon, 1991; Winter and Szulanski, 2001; Rerup and Spencer, this handbook). More recently, the role of cognition in routines has been observed and researchers start to scrutinize elements and parts of routines instead of regarding them as 'entities' (Howard-Grenville and Rerup, 2017). Within the context of Routine Dynamics, the original focus on cognition has moved to the background, but has not been ignored completely (Lazaric and Denis, 2005; Rerup and Feldman, 2011). Within the Routine Dynamics perspective, the notion of reflective action, thinking and debriefing about the content of the performance have been identified as critical for envisaging new and reconsidering current patterns of interdependent actions (Bucher and Langley, 2016; Dittrich et al., 2016; Kiwan and Lazaric, 2019). With a distinct but complementary frame, Archer (1995) defines the notion of self-talk as diverse 'modes of internal conversation' which can be helpful for understanding how the voice within routines might potentially (or might not) reframe existing patterns of routines and introduce new 
actions. Indeed, reflexivity and mindfulness, as has been demonstrated in prior works (Levinthal and Rerup, 2006; Salvato, 2009; Turner and Rindova, 2012), have the potential to shape both cognition and the representation of routines and provide different insights for reshaping cognition in RD.

The aim of this chapter is to provide an overview of the role of cognition and to suggest an agenda for research into the role for cognition within the Routine Dynamics perspective. To this end, I will start with the treatment of cognition in classical studies on routines from the Carnegie School, which puts cognition at the center. I will show how and where cognition has been addressed in Routine Dynamics studies and I will propose and develop the notion of reflection as a way of returning cognition to the forefront of Routine Dynamics studies in a way that is compatible with the basic assumptions of the Routine Dynamics approach. The outline of this chapter is as follows.

In section 2, I present the point of departure for the cognition in classical routines studies. In section 3, I review the evidence and reveal what we know about cognition in Routine Dynamics and what remains to be investigated. In the following section, I argue that Archer's work should be reconsidered to understand how reflexivity and cognition are built through new patterns of actions. I show that Archer might be the starting point for a reinvestigation of the link between agency and structures, and that cognition should be reconsidered in the context of the enactment of actions and the different solutions to concrete and situated problems.

\section{The role of cognition in classical routine studies}

Simon's (1955) vision of cognition is the classic frame for understanding the underlying assumptions related to cognition and problem solving. The notion of organizational docility is one of the main assumptions related to understanding this vision of routines and their 
foundation. Initially, the study of cognition was limited to the Carnegie School and Nelson and Winter's (1982) organizational knowledge, knowledge articulation and knowledge replication framework for building and diffusing routines (Becker et al., 2005; Winter and Szulanski, 2001, Gupta et al., 2015; Winter, 2003). More recently this debate has been reexplored by the Routine Dynamics community.

\subsection{Cognition, problem-solving and routines}

Simon's frame is focused on the process of decision-making and how people make decisions under conditions of limited computational and informational resources (Simon, 1955, 1959; Brette et al., 2017). In an attempt to get a better understanding of the human mind, Simon collaborated with Allen Newell and produced some decisive and pioneering work in cognitive psychology and artificial intelligence. The use of simulation tools produced some interesting results which can be considered a turning point in Simon's career and a departure from his early research (Brette et al., 2017). In 1958, Simon and James G. March published their famous book entitled Organizations and held the first RAND summer seminar on simulation techniques. These developments in the behavioural foundations of organizations and the exploration of the human mind resulted in important work on bounded rationality and a specific vision of problem solving.

In his view of the decision-making process Simon underlines the implementation of cognitive mechanisms which to some extent are activated automatically. Simon further developed an opposition between habit and decision, and coined the terms 'routinized responses' versus 'problem-solving responses' (March and Simon, 1958). He argued that 'habit permits the conservation of mental effort by withdrawing from the area of conscious thought those aspects of the situation that are repetitive $[\ldots .$.$] and permits attention to be devoted to the$ novel aspects of a situation requiring decision' (Simon, 1947 [1976]: 88). In this classical 
frame, rationality required a conscious choice between diverse options, and a choice process in which habits support rationality in the sense that they enable cognitive resources to be devoted to novel and complex situations. However, habits are ambiguous in that they both support rationality and are an obstacle to its development. For Simon: 'In most cases, there seems to be a close relation [...] between the spheres of attention and of rationality. That is, docility is largely limited by (1) the span of attention, and (2) the area within which skills and other appropriate behaviors have become habitual. Hence to a considerable extent, the limits upon rationality [...] are resultants of the limits of the area of attention' (Simon (1947 [1976]: 90).

\subsection{Docility - an important prerequisite for problem-solving and organizational memory}

The notion of docility was important for Simon in this process and refers to a situation in which '[the individual ] observes the consequences of his movements and adjusts them to achieve the desired purpose.' Docility, then, is characterized by a stage of exploration and inquiry, followed by a stage of adaptation (Simon, 1947 [1976]: 85). In addition, Simon underlined the social nature of man: human beings are members of social groups whether organizations or society, and this belongingness to a social order is not neutral for individuals (Simon, 1947 [1976]: 102).

This vision of 'framed' social interactions and docility towards organizational goals, appears to be the solution to the limited cognitive resources of human beings. This epistemological foundation allowed Simon to focus on the decision-making process, and more specifically on the issue of problem solving (Newell and Simon, 1972; Sent, 2000). In this context:

Habits and routines may not only serve their purposes effectively, but also conserve scarce and costly decision-making time and attention. For that reason, a very large part of an organization's activities (or a person's) is likely to proceed according to 
established rules and routines, which may be reviewed at shorter or longer intervals for possible revision. (Simon, 1947 [1997]: 89).

Some dimensions of Simon's legacy related to organizational and administrative processes are reflected in Nelson and Winter's (1982) work where routines are the organizational memory allowing firms to accumulate knowledge and knowhow to achieve coordination and cognitive efficiency. This legacy was revived by the introduction of the Schumpeterian vision of innovation and entrepreneurship, and an evolutionary perspective on the original Carnegie School framing. The notion of routines was closely linked to the expansion and replication of knowledge from an entrepreneurial perspective. Cognition was both a survival mechanism and a behavioural regularity in a competitive environment but not really a process of knowledge creation by individuals (Winter, 1964). The point of departure was important but not sufficient for explaining how individuals are acting to renew and to reconsider knowledge in their daily actions. According to this approach, notions of reflection and mindfulness were critical to reconsidering knowledge and cognition as something which is not inert but enacted and performed by actors (Lazaric and Denis, 2001, 2005; Levinthal and Rerup, 2006), and to go beyond the classic vision of routines as procedures that memorize knowledge and give some behavioural efficiency (Cohen, 1991; Cyert and March, 1963). In this classical vision of the firm, routines and cognition were designed as a fixed point that requires little change to gain cognitive efficiency. This vision has been reconsidered to some extent by Nelson and Winter (1982) but the main assumption remains that cognitive efficiency is essential for organizations to work smoothly. New empirical evidence has shown that a new frame for opening the black box of cognition should be built and this reconsideration of routines starts with mindfulness, individuals' voice and endogenous change (Pentland and Rueter, 1994; Feldman 2000). 


\section{What we know about cognition in RD}

Feldman and Pentland (2003: 96) define routines as 'recognizable patterns of interdependent actions carried out by multiple actors' and highlight that the main outcome of this is a 'new understanding' about the relation between action and patterns as constituted by and through actions. For many years, the Routine Dynamics community gave cognition little attention, focusing rather on understanding the concept of routines and the potential for individual agency (Feldman, 2000; Feldman and Pentland, 2003; Pentland and Rueter, 1994; Feldman et al., 2016).

Making 'action' the essential building block of the micro-level dimension of routines allows us to study the creation of new routines from an agency perspective, as emerging from the 'relationship between specific actions and patterns of action' (Pentland et al., 2012: 1485), and opens a window to reconsider patterns of action and their cognitive roots. Along these lines, the following section reveals that the Routine Dynamics community has provided robust and significant empirical evidence on the role of artefacts notably for guiding actions and patterns of actions, intentionality and reflection and has provided new empirical evidence on cognition.

\subsection{The role of artefacts in cognition}

Artefacts should not be ignored since they articulate knowledge and transform potential skills into future capabilities (Lazaric et al., 2003; D'Adderio, 2008; Cacciatori, 2012). It has been shown that artefacts are a source of memorization at the interface between the performative and ostensive aspects of routines (Cacciatori 2008, 2012; D’Adderio 2008, 2011). Much empirical evidence has accumulated about the critical role of artefacts as mediators and manifestations of cognition (see chapters by D'Adderio, Sele and Glaser in this handbook). For instance, Orlikowski (1992) explains how human agency is mediated by manmade 
objects, while D'Adderio (2008) and Salvato (2009) discuss the criticality of how agents create and make use of artefacts in their practice to maintain or change routines and how artefacts serve to create external memories which are distributed among the actors. D'Adderio (2011: 197) highlights artefacts and acknowledges their importance as providers of '... the glue that can hold action patterns together'. Cacciatori (2012) suggests that rather than being considered individually, artefacts should be seen as systems of artefacts involved in the creation of routines. She demonstrates that the emergence of new routines is mediated by the development of systems of artefacts able to reproduce problem solving structures at the heart of the routinization process. Furthermore, artefacts play a critical role in the building of 'standard operating procedures' (Lazaric and Denis, 2005; D’Adderio, 2008). They mediate routines and skills and transform experience into potential new patterns (Cacciatori, 2012), paying attention to the micro-processes 'through which patterns of actions are created and recreated from within' (Dionysios and Tsoukas, 2013: 184).

The role of actors in designing artefacts and routines by inscribing their vision of ways of doing things is also an important factor (Glaser, 2017). Artefacts encode knowledge and act as mediators between skills and routines (Cacciatori, 2012). They are rarely used in isolation; rather, they are used in systems which are important for stabilizing the firm structure. For instance, Lazaric and Denis (2005) show that handbooks describe ways of doing things, relying on sub groups of artefacts or subtasks such as the writing of procedures which convey and articulate knowledge at each step in the process. In short, systems of artefacts are arranged and are mutually reinforcing to stabilize existing performance and identify patterns that co-shape routines (Cacciatori, 2012). Some artefacts 'contain a visual representation of knowledge. They include procedure, manual, reports, technical drawings and virtual prototypes' (Cacciatori, 2012: 1362) and include the product and also the process representation, that is, the way things are done and how and why things are done in a certain 
way, and why they make sense to the actors. These cognitive tools are entangled at the heart of the performative and ostensive dimension of routines (D'Adderio, 2011). Relatedly, Parmentier et al. (2020) show for the biocontrol case (pesticides without chemical inputs) that the process of permanent adaptation is critical for artefacts involved in stabilizing the process. Further, the use of artefact-as-coordination tool enables progress towards an ideal future situation (developing a new activity in line with the firm's needs) and borrows from past situations (existing norms from the regulatory domain). Depending on the situation, the artefacts are viewed either as goals (ends-in-view) or as means (a spreadsheet, a database), showing that means and ends-in-view are not fixed but are rather 'fluid and flexible' (Dittrich and Seidl, 2018) because these elements are in the process of becoming (Tsoukas and Chia, 2002).

\subsection{Replication and emergence of new routines}

When organizations are faced with ill-structured problems and unstructured decision processes, building new routines may be more complicated (Obstfeld, 2012). In this case, the issue is not replicating the initial knowledge or resources but finding new patterns.

Replication is complex and implies some degree of novelty for redesigning and adapting to the new context since knowledge cannot be replicated but must be discovered during this process (Becker et al., 2006; see chapter by Blanche and Cohendet in this handbook).

Knowledge replication and codification are built through a process of knowledge transfer and transformation which generates negotiation of its core and adaptation of its scope (Lazaric et al, 2003; D'Adderio, 2014). D'Adderio (2014) shows precisely why agency is critical and that goals may differ in the process leading to potential transformation of the template and a process of adjustment during knowledge replication.

Creating new routines is an effortful task since it involves the co-shaping of the ostensive and performative aspects of the routine. This duality represents a critical period of learning where 
the routines to be performed require the strong involvement of the actants through trial and error learning, experimentation, and improvisation to reduce uncertainty while articulating and trying to codify some of the knowledge. More precisely, Rerup and Feldman (2011) highlight the combination of cognition and action for the emergence of new routines and the process of permanent adjustment that actors implement as they engage in trial and error learning. In short "[e]ach trial either replaced a specific performance in the (recruitment) routines with another specific performance or added a new performance to the existing set of performances" (Rerup and Feldman, 2011: 603), showing it is not a fixed but rather a heterogeneous process which leaves space for creativity when complex problems arise. These empirical findings show that in the context of difficult problems "people are more like firefighters than they are like strategic decision makers" (Rerup and Feldman, 2011: 604).

\subsection{Intentionality of actors in the building of new patterns}

Intentionality is important for solving problems and for cognition, but the vision of the intentionality is far from neutral. In that context, Dittrich and Seidl (2018), drawing on Dewey (1957), suggest that intentionality is not the product of the mind but is dynamically enacted in the performance of routines with ends in view. Ends in view are constitutive of action and help actors to experiment and to adjust their ends to the existing means. Thus 'ends-in-view' and means are mutually constitutive and 'this view allows us to appreciate intentionality not as something "of the mind" (Chia and Holt, 2006: 648) but as something that is dynamically enacted in routine performances. Consequently, routine participants "can develop a sense of purpose from action without consciously reflecting on action" (Dittrich and Seidl, 2018: 115). Thus, the construction of new patterns of actions is rooted in the practice itself rather than being the result of a pure process of reflection. This creates a sense of purpose from action without deliberating over the action. This new vision has some resonance with Cohen's 
(2007) vision of the interdependence between ends and means and the mutually constitutive vision of agency and structure (Emirbayer and Mische, 1998).

Along similar lines, Turner and Rindova (2012) show the need to maintain dual ostensive patterns to target diverse goals (targeted consistency or flexibility) which facilitate flexible and mindful responses within task coordination. They show a subtle combination of mindless and mindful behaviours according to goals and means during the performance of routines (Turner and Rindova, 2012). Here, cognition is linked directly to coordination, and modulated according to ends and means-in-view to provide flexible ostensive patterns which allow actors to handle task (in)consistency and challenges. This work echoes the vision of a continuum between mindful and less mindful behaviours rather than the separation between these two categories (Levinthal and Rerup, 2006).

\subsection{Reflection as a critical step for cognition}

Talking about routines is a way of "reflecting on what they are doing, and doing different things (or doing the same things differently) as a result of the reflection" (Feldman, 2000: 625). Feldman (2016: 14) shows there is no one single intentionality in routine creation but that actors perform and solve problems in relation to what others do. This relational view explains the interdependence between actors experimenting with actions. To resolve organizational problems, actors use 'collective discussions' to negotiate the content of the knowledge and their role in the implementation of new quality systems (Lazaric and Denis, 2005). Dittrich et al. (2016), in the case of a pharmaceutical start-up, highlight the role of 'reflective talk' in routine change and show how talking reveals diverse opportunities for routine changes.

Bucher and Langley (2016) discuss "the role of collective reflection in routine change", where spaces and "bounded social settings" influence the ostensive and performative aspects 
of routines (Bucher and Langley, 2016: 597). They consider two types of spaces in which actors "engage in deliberate efforts to alter both performances and abstract aspects" (Bucher and Langley, 2016: 594). Experimental spaces enable the integration of new actions into a new routine formation while reflective spaces aim to conceptualize the routine. While reflective spaces can involve a set of distant actors involved in the original routine, experimental spaces are "nested within the surrounding structure $[\ldots]$ cover subroutines, including actors who perform these subroutines but not others" (Bucher and Langley, 2016: 600). Experimental spaces involve testing concepts and challenging the coordinating mechanisms already in place. During experimentation by a surgical team using a robot, Kiwan and Lazaric (2019) show that actors try to build new ostensive and performative aspects of the surgical routine and talk about each of the sub-elements to find new ways of doings things. The experimental space helps the actors to solve the problem step by step while having the opportunity to stop the robotic surgery if the process becomes dangerous and discuss a safer option.

\section{A roadmap for the coming years}

The notion of agency, which contrasts starkly with Carnegie School thinking, enables a new way of defining and naming routines with actors who are knowledgeable and often reflexive (Feldman et al., 2016). This provides a new vision of cognition for understanding the process and conditions allowing such reflexivity (Dittrich et al., 2016; Feldman, 2016). In order to take the study of the role of cognition a step further, we might draw on the work of Archer (2003), who highlights diverse sources of human mental operation in a realist framework combining the notion of internal conversation with the concept of action. As such, she offers a nice entry to understanding the human mind in action and the limits to individual decision making, allowing a potential renewed source of inspiration for Routine Dynamics. 


\subsection{Reflection without neglecting the role of structures in Routine Dynamics}

Archer (2003) illustrates how personal projects are formed and how they mediate the exercise of systemic constrains and enablements. Inspired by Roy Bhaskar's critical realism, she develops a theory of the emergence, reproduction and transformation of cultural systems and social structures and analyses how human beings develop their personal and social identities as they pursue their ultimate concerns in more or less coherent way. By developing this argument she enters into the cognitive black box to understand human cognition and personal decision. She advances an alternative theory to give life to agency and structures that are interlinked and vibrant entities which can be observed when individuals struggle and face a problem. These diverse 'self- talk' and tensions during problem solving show the difficulty of building patterns. Indeed "patterns are constituted in and through action and emphasizing the constitutive nature of action in the process of patterning draws our attention to the work of recognizing and articulating or narrating these patterns" (Feldman, 2016: 40).

It has been argued that "practice-based studies of routines have tended to give primacy to agency and have provided a less developed account of the role of structure in the dynamics of routines - partly as a reaction to a view of routines as rigid and automatic. " (Turner and Cacciatori, 2016:89). This opens the door to understand the place of structures when routines are observed as a process of performing and patterning and to scrutinize tensions within and through actions. There are many types of structures, of course, from institutions, to social norms, to technological paradigms (see chapter by Howard-Grenville and Lodge in this handbook). According to Dosi (1988), structures and scientific institutions contextually define the needs that are meant to be fulfilled, and the scientific principles and technology to be used in a given industry. Dosi (1988:1127) defines a technological paradigm 'as an exemplar - an artifact that is to be developed and improved ....and a set of heuristics'. Heuristics support problem solving and create shortcuts which allow individuals and organizations to operate in 
situations of uncertainty (Kahneman et al., 1982). Parmentier et al. (2020), researching a startup in the biocontrol industry, show how much effort was involved in creating new routines, as the company had to translate all the biological practices in reference to the old paradigm (based on chemical principles) and negotiate their validity and existence. I argue here that we need to investigate this evolutionary process in more depth, including the creation of new path-dependent patterns of actions to understand how new ostensive patterns are accepted, validated, built and re-built in a dynamic process. In this direction, Pentland and Ju Jung (2016) provide significant insights which need to be consolidated to get a better understanding of the weight of new heuristics in patterning and of the current heuristics performed by actors.

\subsection{Diverse levels of reflexivity for actors}

Archer (2003) acknowledges diverse forms of 'self-talk' and provides a summary of diverse modes of mental operation across individual personality types. First, 'communicative reflexive' individuals distrust their own internal dialogues. Their decisions and cognition are co-shaped by 'similars and familiars' who maintain a 'micro-world' around them preventing them from exploiting opportunities, and thus maintaining some degree of social immobility (Archer, 2003: 166-167). Second, individuals may be 'autonomous reflexives' and show decisiveness in their actions. These groups of individuals weigh up the opportunities and constraints in the objective situations they face. They have past experience of contextual discontinuity in action and rely on their own judgement (Archer, 2003: 212). Third, 'meta reflexives', like autonomous reflexives, also have experience of continual discontinuity and rely on their own judgements. However, 'meta reflexives' tend to have a strong idealized view of how they should be: their main concern is how to live in a context in which they can express certain ideals they hold (Archer, 2003: 258). Meta reflexives have a very critical orientation toward objective structures and situational constraints and try to maintain their ideal (their ostensive vision) and reject situations where the benefits are inconsistent with their 
ideals. This high vision of ideals implies difficulty related to their ambitions in practice. In this context, Archer refers to the 'fractured' reflexive', who engage in self-talk but are unable to form a plan or action or project and deal with it (Archer, 2003: 303-304).

These diverse categories of reflexivities are important for observing how an actor lacking mindfulness (or discursive awareness) performs habitual actions and acts on habitual beliefs, and how individuals can struggle to instantiate and enact their ostensive vision. Archer suggests that actors who are 'communicatively reflexive' rather than 'meta reflexive' have less faith in their ability to reach a decision based on their own self-talk. Exposure to a greater variety of objective contexts can produce situations where habitual actions are called into question, and habitual beliefs may be exposed to internal conversation (or not). 'Meta reflexive' actors are more oriented to 'treating its habitual beliefs as objects to be transformed into explicit "concerns" in a process of self-examination, and less oriented to using habitual beliefs and automatic judgment' (Fuller, 2013: 125). Huge uncertainties, such as those described in the literature of Grand Challenges (Ferraro et al., 2005), require that individuals and organizations must be 'active experimenters' and identify some actions while solving new problems (for instance, in agricultural practice, how to reduce mildew on vines using nonchemical treatments). The need to find new patterns and to handle Grand Challenges among other issues may create significant internal and external tensions during experimentation.

\subsection{Solving problems differently through and within actions and agency}

Archer's discussion of the diversity of levels of internal talk is important in the context of how actors question the ostensive level of routines, what their ideal vision of a routine should be and the degree of novelty in performative routines designed to change elements of their actions and practices. Some actors, identified by Archer as more inclined to engage in 'meta reflexive' talk, will be better able to reframe the ostensive and performative levels of routines 
because they are more prone to coping with discontinuity. Along similar lines, Pentland (1995) proposed 'grammars of action' to describe routines where grammars define the set of possibilities and variations related to a specific language, and the action is the routines required to achieve the task (Pentland, 1995; Pentland and Rueter, 1994). Indeed, “an organizational routine is not a single pattern but rather a set of possible patterns" (Pentland and Rueter, 1994: 491).

This processual vision of routines is important for building cognition, actions and changes. Feldman (2000: 613) suggested that routines are not only 'effortful accomplishments' but also 'emergent accomplishments' and 'works in progress rather than finished products'. In other words, routines do not only involve mindful effort, they are enacted repeatedly, and each repetition provides stimuli for variation and change. Feldman and Pentland (2003) investigate the nature of the relation between action and patterns of routines and observe that the identification of ostensive aspects constituted of and by actions shows that enacted patterns may be more or less consistent with written or abstract patterns. Thus, solving problems and ways of solving them opens diverse opportunities to challenge (or not) habitual beliefs and patterns of interdependent actions among actors.

Archer goes a step further and identifies the nature and context of this voice within routines, helping us to understand cognition and actions through patterning. For Archer, the human as a 'person' has an inner conversation not promoted by objective structures and related to his or her own causal powers (Archer, 1995, 2003; Fuller, 2013). Archer (2003) identifies diverse modes of 'self-talk' from her interviews and scrutinizes the place of diverse habitual beliefs and the relative autonomy of individuals in society, helping us to understand their ontological vision for acting and solving problems. Indeed, and in contrast to Simon's view of docility, individuals depend on but are not reducible to social structures. 


\section{Conclusion}

Routine Dynamics provides new empirical evidence on cognition that deserves greater attention. The importance of artefacts, of intentionality and diverse levels of reflection provide new ways to reconsider this issue and to understand some degree of mindfulness at the ostensive and performative levels of routines. Cognition within the Routine Dynamics frame is built within and during action and is no longer considered as a product of the mind. These insights provide a new point of departure from the established classical studies of cognition. New patterns are built showing how cognition is dynamically rooted in the performance of action and brought into the action by actors. Reflection is one of the critical elements for linking action to the patterns of actions. Archer, among others, provides interesting insights that can be useful for responding to the question "how do we do patterning" (Feldman, 2016: 39), and for understanding the construct of intersubjective meaning and the role taken by those actions in exploring the process of patterning (Dionysiou and Tsoukas, 2013). In short, despite significant empirical results, a lot of work remains to be done to scrutinize the impact of the mutual constitution of performative and ostensive aspects of routines as well as the impact of 'cognition in the wild' within the Routine Dynamics framework. Nevertheless, a great deal has already been achieved in this direction, showing the capacity of Routine Dynamics to renew its theoretical framework by integrating new elements of observations collected by researchers. 


\section{References}

Archer, M. (1995), Realist Social Theory: The Morphogenetic Approach, Cambridge University Press, Cambridge.

Archer, M. (2003), Structure, Agency and the Internal Conversation, Cambridge University Press, Cambridge.

Archer, M. S. (2007), Making Our Way Through the World, Cambridge: Cambridge University Press.

Becker, M.C., Knudsen, T. \& March, J.G. (2006). Schumpeter, Winter, and the sources of novelty. Industrial and Corporate Change, 15, 353-371.

Bertels, S., Howard-Grenville, J., \& Pek, S. (2016). Cultural molding, shielding, and shoring at Oilco: The role of culture in the integration of routines. Organization Science, 23, 573-593.

Brette, O., Lazaric, N. \& de Vierera, V. (2017). Habit, Decision Making and Rationality: Comparing Thorstein Veblen and Early Herbert Simon, Journal of Economic Issues, (3), 567-587.

Bucher, S. \& Langley, A. (2016). The interplay of reflective and experimental spaces in interrupting and reorienting routine dynamics. Organization Science, 27, 594-613.

Cacciatori E (2012) Resolving conflict in problem-solving: Systems of artefacts in the development of new routines. Journal of Management Studies, 49, 1559-1585.

Cohen, M.D. (1991). Individual learning and organizational routine: emerging connections. Organization Science, 2 (1), 135-139.

Cohen, M.D. (2007). Reading Dewey: Reflections on the study of routine. Organization Studies, 28(5), 773-786.

Cyert, R.M. \& March, J.G. (1963/1992). A Behavioral Theory of the Firm. Cambridge, MA: Blackwell Business.

D'Adderio, L; (2011) Artifacts at the centre of routines: Performing the material turn in routines theory. Journal of Institutional Economy, 7,197-230.

D'Adderio, L. (2008) The performativity of routines: Theorising the influence of artefacts and distributed agencies on routines dynamics. Research Policy 37,769-789.

D'Adderio, L. (2014). The replication dilemma unravelled: How organizations enact multiple goals in routine transfer. Organization Science, 25, 1325-1350.

Deken, F., Carlile, P.R., Berends, H., \& Lauche, K. (2016). Generating novelty through interdependent routines: A process model of routine work. Organization Science, 27, 659-677.

Dionysiou, D.D. \& Tsoukas, H. (2013). Understanding the (re)creation of routines from within: A symbolic interactionalist perspective. Academy of Management Review, 38, 181-205.

Dittrich, K., Guerard, S., \& Seidl, D. (2016). Talking about routines: The role of reflective talk in routine change. Organization Science, 27(3), 678-697.

Dittrich, K, \& Seidl, D. (2018). Emerging Intentionality in Routine Dynamics: A Pragmatist View. Academy of Management Journal, 61, 111-138. 
Dosi, G. (1982). Technological paradigms and technological trajectories. Research Policy, 11, 147-162.

Dosi, G., (1988). Sources, Procedures, and Microeconomic Effects of Innovation, Journal of Economic Literature, 26(3),1120-1171.

Emirbayer, M. (1997). Manifesto for a Relational Sociology. American Journal of Sociology $103,281-317$.

Emirbayer, M. \& Mische, A. (1998). What is agency? American Journal of Sociology, 103(4), 962-1023.

Feldman, M.S. (2000). Organizational routines as a source of continuous change. Organization Science, 11(6), 611-629.

Feldman, M. S., \& Rafaeli, A. (2002). Organizational routines as sources of connections and understandings. Journal of Management Studies, 39(3), 309-331.

Feldman, M.S. (2003). A performative perspective on stability and change in organizational routines. Industrial and Corporate Change, 12(4), 727-752.

Feldman, M.S. (2016). Routines as process: Past, present, and future. In J. Howard-Grenville, C. Rerup, A. Langley, and H. Tsoukas, eds., Organizational Routines: How They are Created, Maintained, and Changed. Oxford, UK: Oxford University Press, pp. 23-46.

Feldman, M.S. \& Pentland, B.T. (2003). Reconceptualizing organizational routines as a source of flexibility and change. Administrative Science Quarterly, 48, 94-118.

Feldman, M. S.\& Orlikowski,. W. J. (2011). Theorizing Practice and Practicing Theory. Organization Science 22(5),1240-1253.

Feldman, M.S., Pentland, B.T., D'Adderio, L., \& Lazaric, N. (2016). Beyond routines as things: Introduction of the special issue on routine dynamics. Organization Science, 27(3), 505-513.

Fuller, C. (2013). Reflexivity, relative autonomy and the embedded individual in economics. Journal of Institutional Economics, 9(1), 109-129.

Ferraro, F., Etzion, D., \& Gehman, J. (2015). Tackling Grand Challenges Pragmatically: Robust Action Revisited. Organization Studies, 36(3), 363-390.

Glaser, V.L. (2017). Design performances: How organizations inscribe artifacts to change routines. Academy of Management Journal, 60, 2126-2154.

Greve, H.R. (2008). Organizational routines and performance feedback. In: Becker MC (ed) Handbook of organizational routines. Edward Elgar Publishing Limited, Northampton, pp 187-204.

Gupta, A., Hoopes, D.G., \& Knott, A.M. (2015). Redesigning routines for replication. Strategic Management Journal, 36, 851-871.

Howard-Grenville, J.A. (2005). The persistence of flexible organizational routines: The role of agency and organizational context. Organization Science, 16(6), 618-636.

Howard-Grenville, J.A. \& Rerup, C. (2017). A process perspective on organizational routines". In A. Langley \& H. Tsoukas eds, Sage Handbook of Process Organizational Studies, Sage Publications, London, UK, pp. 323-339.

Kahneman, D, Slovic, P. \& Tversky, A. (eds.) (1982). “Judgment under uncertainty: heuristics and biases", Cambridge University Press, UK. 
Kiwan, L. \& Lazaric, N. (2019). Learning a new ecology of space and looking for new routines: Experimenting robotics in a surgical team. In M.S. Feldman, L. D'Adderio, K. Dittrich, and P. Jarzabkowski, eds., Routine Dynamics in Action: Replication and Transformation. Bingley, UK: Emerald Publishing, pp. 173-189.

Lazaric, N., Mangolte, P-A, Massué, M-L (2003). Articulation and codification of collective know-how in the steel industry: Evidence from blast furnace control in France. Research Policy 32, 1829-1847.

Lazaric N., \& Denis, B. (2001). How and why routines change: some lessons from the articulation of knowledge with ISO 9002 implementation in the food industry. Economie et Sociétés, 585-612.

Lazaric N., \& Denis, B. (2005). Routinization and memorization of tasks in a workshop: The case of the introduction of ISO norms. Industrial and Corporate Change, 14,873-896.

Lazaric, N. (2008). Routines and routinization: An exploration of some micro-cognitive foundations. In M. C. Becker, ed., Handbook of Organizational Routines. Cheltenham, UK: Edward Elgar, pp. 205-227.

Lazaric, N. (2011). Organizational routines and cognition: an introduction to empirical and analytical contributions. Journal of Institutional Economics, 7 (2), 147-156.

Levinthal, D. A., \& Rerup, C. (2006). Crossing an apparent chasm: Bridging mindful and less mindful perspectives on organizational learning. Organization Science, 17, 502-513

Nelson, R.R, \& Winter, S.G. (1982). An Evolutionary Theory of Economic Change. Cambridge, MA: Harvard University Press.

March, J. \& Simon H., (1958). Organizations, NY: Wiley, 2nd ed., Oxford: Blackwell Publishers, 1993

Newell, A, \& Simon H.A (1972). Human Problem Solving. Englewood Cliffs, NJ: PrenticeHall.

Orlikowski, W.J. (1992). The duality of technology: Rethinking the concept of technology in organizations. Organization Science, 3, 398-427.

Parmentier, A., Lazaric, N., Cajaiba-Santana, G. (2020). The effortful process of routines emergence: The interplay of entrepreneurial actions and artefacts, forthcoming in Journal of Evolutionary Economics.

Parmigiani, A., \& Howard-Grenville, J. (2011). Routines revisited: Exploring the capabilities and practice perspectives. Academy of Management Annals, 5(1), 413-453.

Pentland, B.T. (1992). Organizing moves in software support hot lines. Administrative Science Quarterly, 37, 527-548.

Pentland, B.T. \& Reuter, H.H. (1994). Organizational routines as grammars of action. Administrative Science Quarterly, 39, 484-510.

Pentland, B.T. (1995). Grammatical models of organizational processes. Organization science, 6(5) 541-556.

Pentland, B.T.\& Feldman, M.S. (2005). Organizational routines as a unit of analysis. Industrial and corporate change, 14(5) 793-815.

Pentland, B.T.\& Feldman, M.S. (2008). Designing routines: On the folly of designing artifacts, while hoping for patterns of action. Information and organization, 18(4), 235250. 
Pentland, B.T.\& Ju Jung, E. (2016). Evolutionary and Revolutionary Change in PathDependent Patterns of Action, in Organizational routines: how they are created, maintained, and changed. eds. J. Howard-Grenville, C. Rerup, A. Langley, and H. Tsoukas (Oxford: Oxford University Press), pp. 96-113.

Possas, M.L, Salles-Filho, S.\& Silveira, da J.M. (1996). An evolutionary approach to technological innovation in agriculture: Some preliminary remarks. Research Policy, 25,933-945.

Rerup, C. \& Feldman, M.S. (2011). Routines as a source of change in organizational schema: The role of trial-and-error learning. Academy of Management Journal, 54(3), 577-610.

Salvato, C. (2009). Capabilities unveiled: The role of ordinary activities in the evolution of product development processes. Organization Science, 20, 384-409.

Salvato, C.\& Rerup, C. (2011). Beyond collective entities: multilevel research on organizational routines and capabilities. Journal of Management, 37, 468-490.

Sent, E.-M. (2000). Herbert A. Simon as a Cyborg Scientist. Perspectives on Science, 8, 4, 380-406.

Simon, H.A. [1947] 1976. Administrative Behavior. New York, NY: Free Press, $3^{\text {rd }}$ edition,.

Simon, Herbert A. [1947] 1997. Administrative Behavior. New York, NY: Free Press, $4^{\text {th }}$ edition,

Simon, H.A. (1955). A Behavioral Model of Rational Choice. Quarterly Journal of Economics $69,1,99-118$.

Simon, H. A. (1956). Rational Choice and the Structure of the Environment., Psychological Review 63, 2,129-138.

Simon, H. A. (1957). Models of Man: Social and Rational -Mathematical Essays on Rational Human Behavior in a Social Setting. New York, NY: Wiley.

Simon, H.A. (1959). Theories of Decision-making in Economics and Behavioral Science. American Economic Review, 49, 53-283.

Simon, H. A. (1991). Theories of Bounded Rationality. In Decision and Organization, edited by C.B. McGuire and Roy Radner, Amsterdam: North-Holland Publishing pp. 161176.

Simpson, B. \& Lorino, P. (2016) Re-viewing routines through a Pragmatist lens.in Organizational routines: how they are created, maintained, and changed. eds. J. Howard-Grenville, C. Rerup, A. Langley, and H. Tsoukas (Oxford: Oxford University Press, pp.47-70.

Tolman,E. C. (1932). Purposive Behavior in Animals and Men. New York, NY: The Century Co,

Tsoukas, H.,\& Chia, R. (2002). On organizational becoming: Rethinking organizational change. Organization Science, 13, 567-582.

Turner, S.F. \& Rindova, V. (2012). A balancing act: How organizations pursue consistency in routine functioning in the face of ongoing change. Organization Science, 23(1), 24-46.

Turner, S. F., \& Cacciatori, E. (2016). "The multiplicity of habit: implications for routines research" in Organizational routines: how they are created, maintained, and changed. eds. J. Howard-Grenville, C. Rerup, A. Langley, and H. Tsoukas (Oxford: Oxford University Press), pp.71-95. 
Winter S.G.\& Szulanski, G. (2001) Replication as strategy. Organization Science, 12,730743.

Winter, S. G. (1964). Economic "natural selection" and the theory of the firm. Institute of Public Policy Studies, University of Michigan 4, 225-272.

Winter, S. G. (2013). Habit, Deliberation, and Action: Strengthening the Microfoundations of Routines and Capabilities. The Academy of Management Perspectives, 27, 2, 120-137. 